\title{
Endotracheopulmonary Instillation, Powder for Suspension Dosage Form
}

National Cancer Institute

\section{Source}

National Cancer Institute. Endotracheopulmonary Instillation, Powder for Suspension

Dosage Form. NCI Thesaurus. Code C149491.

Solid preparation consisting of one or more powders intended to be dispersed in the specified liquid to obtain an endotracheopulmonary instillation suspension. 